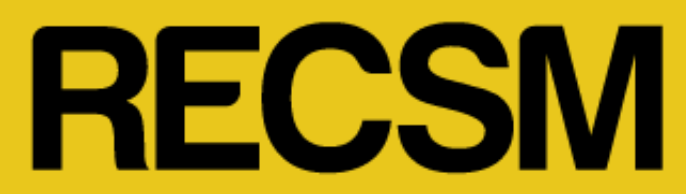

Research and Expertise Centre for Survey Methodology

\title{
Matching pre-processing of split- ballot survey data for the analysis of double standards
}

\section{Bruno Arpino}

RECSM Working Paper Number 47

February 2016 


\title{
Matching pre-processing of split-ballot survey data
}

\section{for the analysis of double standards}

\author{
Bruno Arpino \\ Department of Political and Social Sciences and Research and Expertise Centre for Survey \\ Methodology (RECSM), Universitat Pompeu Fabra; \\ Carrer Ramon Trias Fargas 25-27, 08005 Barcelona, Spain; bruno.arpino@upf.edu
}

\begin{abstract}
Split-ballot data are often used to study double standards. The key problem of this design is that individual double standards cannot be identified. We propose a simple two-step approach based on a matching pre-processing of the data to estimate individual double standards. Once this preliminary first step is completed, any statistical technique (e.g., regression models) can be applied on the new data. We illustrate the method with an application concerning gender double standards on attitudes toward age at leaving home using data from the third round of the European Social Survey. We show that the proposed method simplifies regression analyses of the effects of covariates on double standards and offers new opportunities for research on double standards.
\end{abstract}

\section{Keywords}

matching, double standards, split-ballot design, gender, European Social Survey 


\section{Introduction}

In this paper we propose a simple two-step approach for the analysis of double standards using split-ballot survey data. A double standard refers to the use of different criteria for judging the same trait, behavior or performance of two different groups of people (Foschi 1996). While the focus will be on gender double standards, i.e. on the differential evaluation of men and women, the proposed methodological approach can be applied more generally to evaluate double standards with reference to race, age, economic status, etc.

There is a vast amount of studies in social psychology and other disciplines on gender double standards (e.g., Crawford and Popp 2003; Deutsch and Saxon 1998; Kreager and Staff 2009; Reid, Elliott and Webber 2011; Reiss 1964; Rijken and Merz 2014). Jasso and Webster (1997), for example, investigated double standards in just earnings for men and women workers and found that men were systematically assigned higher just earnings than comparable women. The studies reviewed by Crawford and Popp (2003) highlight a persistent sexual double standard consisting in more sexual permissiveness granted to men (see also Kreager and Staff 2009). Liefbroer and Billari (2010) and Rijken and Merz (2014) found evidence of gender double standards with respect to the acceptance of different demographic behaviours such as living in an unmarried cohabitation or being voluntarily childless.

Quantitative non-experimental studies have used two different types of survey designs to analyze gender-based double standards ${ }^{1}$. In the first type of design, used for example by Reiss (1964), all respondents answer the same questions on the

\footnotetext{
${ }^{1}$ In this paper, we focus on quantitative methods based on survey data. Alternative approaches that have been used for the analysis of gender double standards include experimental research (see e.g., Marks and Fraley 2006) and qualitative methods (see e.g., Loxley 1996).
} 
acceptance of given behaviors with reference to woman and men separately. In this approach, that we label as complete design, asking twice the same question for the two gender target may introduce a bias due, for example, to question order effects, increases interviews duration and cost, as well as probability of non-response. Moreover, non-independence of answers within respondents should be addressed.

The second approach, named split-ballot design, consists in randomly drawing two sub-samples to be assigned to items regarding women and men, respectively (see e.g., Rijken and Merz 2014). The split-ballot design, is a classic way of integrating experimental design and survey of a representative population sample combining the distinctive external validity advantages of representative surveys with the decisive internal validity strengths of the fully randomized experiment (Sniderman and Grob 1996).

The main limitation of the split-ballot design is that it does not allow to identify the existence of double standards at the individual level because each respondent either answer the question regarding men or women, while the other answer is missing. Nevertheless, data from split-ballot surveys can be used to assess the existence of double standards at the level of groups or by imputing the missing answers. The simplest approach consists to use regression models where among the covariates of interest it is included a dummy for the gender of target (see e.g., Rijken and Merz 2014). This approach has some limitations. First, a methodological drawback is that the imputation relies on the goodness of the specified regression model assumptions (e.g., linearity). Second, it makes difficult to fully study the heterogeneity that can characterize double standards. One should, in fact, include all possible interactions between the gender of target dummy and all the other covariates. 
This becomes unfeasible, or difficult for the interpretation of results, when several covariates are included especially in complex models, like multilevel and/or nonlinear models. We propose an alternative and simple two-step approach based on preprocessing the data by matching before multivariate analyses are implemented. We also show that the potential outcome framework (Rubin 1974), developed in the different context of causal inference, can help in conceptualizing the analysis of double standards with split-ballot data.

The proposed approach has several advantages. The imputation is made transparent by the matching procedure and parametric assumptions are avoided. However the most relevant advantages are for the substantive research questions that the approach helps to answer. The imputation step allows to estimate double standards for each individual and these can be directly analyzed. Any technique can be used in the second step. With this approach the study of the (possibly complex) heterogeneity characterizing double standards formation is simplified. We apply this approach to data from the third round of the European Social Survey.

\section{Methods}

Consider a split-ballot design questionnaire where, for expositional simplicity, a single question on attitudes related to the acceptance of a given behavior is included. Assume that we have a random sample of $N$ individual units under study $\left\{t_{i}, y_{i}, x_{i}\right\}_{i=1}^{N}$. $T$ represents the gender of target indicator, that takes the value 1 for respondents assigned to answer the question for males and 0 for those who answer the question for females, $Y$ indicates the observed attitude, and $X$ indicates a set of covariates. Let indicate with $m$ the generic individual assigned to the male target, $m=1 \ldots M$, and $f$ the 
generic individual assigned to the female target, $f=1, \ldots, F$; with $0<M<N, F=N$ $M$. Usually, $M \approx F \approx 1 / 2 N$.

Using the concept of potential outcomes, we can think that independently of the split-ballot assignment, for each individual two (potential) attitudes exist, $Y(1)$ and $Y(0)$, that respectively indicate the attitude of each respondents toward the behavior of males and females. The observed attitudes, $Y$, will be equal to $Y(1)$ for individuals assigned to the male target and equal to $Y(0)$ otherwise: $Y=T^{*} Y(1)+(1-T) * Y(0)$.

The difference (or any other comparison) between the two potential attitudes, $D=Y(1)-Y(0)$ is a measure of double standard. We say that an individual $i$ holds a double standard if $d_{i} \neq 0$. Since each respondent either answers the question for males or females, the individual double standard cannot be observed. We propose to impute the missing attitude using a matching approach. The idea is to use covariates $X$ to find for each individual, $m$, assigned to the males target an "identical" individual, $f$, assigned to the female target. Then the estimated individual double standard is $\hat{d}=y_{m}-y_{f}$. The estimated double standard for those assigned to the female target is obtained similarly. This procedure, known as exact matching, may be unfeasible in the presence of many covariates and/or when some of them are continuous. An approach to deal with this problem, which we will use in the application, is the Coarsened Exact Matching ${ }^{1}$ (CEM; Iacus, King and Porro 2011). The CEM algorithm involves three steps: 1) coarsen each control variable in $X$ as much as the researcher is willing, for the purposes of matching; 2) sort all units into strata, each of which has

\footnotetext{
${ }^{1}$ Alternative matching approaches are available, like propensity score matching, that is widely used in the treatment effect literature (see e.g., Arpino and Aassve 2013).
} 
the same values of the coarsened $X ; 3)$ prune from the data set the units in any stratum that do not include at least one treated and one control unit.

Following these three steps, the researcher can apply any regression method to the matched data (e.g., a regression model). In fact, once we have estimated the variable $D$ for each subject, irrespectively of the specific matching procedure we adopted, we can directly use this new variable in a multivariate analysis.

\section{Data and variables}

To illustrate the proposed approach we use data from the third round of the European Social Survey (ESS-3) conducted in 2006 in 25 European countries. A list of the countries included in the ESS-3 is provided in Table 1. The European Social Survey (ESS) has been developed by fully adopting a comparative perspective and making an effort to construct equivalent questionnaires in the different languages used in the interviews. The first part of the survey, the so-called core module, which remains unchanged over survey rounds, includes questions on trust in institutions, political attitudes, well-being, socio-demographic characteristics, etc. The questionnaire includes also a second part that differs across rounds (i.e. the so-called rotating module). A key innovation of the third round of the ESS is that it includes a module with a split-ballot design named the "Timing of the life course" and containing questions on individuals' attitudes towards life course choices.

This module includes questions on events that can be considered as markers of the transition to adulthood. More specifically, there is a battery of questions that read as follows: "To be considered an adult how important is it for a [man/woman] to [have lived with a spouse or partner/ become a [father/mother]/ have left the parental 
home/ have a full-time job/]?” Answers can be given on a 5-point scale ranging from $1=$ "Not at all important" to $5=$ "Very important". Table 2 provides some descriptive statistics on these variables by country. From the table we can see that double standards seem to exist in many countries but with different degrees. Some countries, like Portugal show very little (and not significant) differences in the average scores by the gender of the target. From Table 2, it also emerges that the stronger double standards arise with respect to the importance of having a full-time job to be considered an adult. A matching pre-processing approach might be very useful to analyse this battery of questions. For example, it could be of interest to find clusters of individuals with similar patterns of double standards with respect to the different life course events. After having pre-processed the data by using a matching algorithm, it would be easy to estimate individual double standards for each of the four dimensions described in Table 2. Subsequently, a cluster analysis could be easily implemented on the new data. This would not be possible using the raw data.

Another set of ESS-3 questions useful to study double standards related to the transition to adulthood pertain to individuals' perception of the appropriate age when a range of life course events should or should not occur. We focus in particular on what an individual believes is the appropriate age of leaving home. To be specific, the question is posed as follows: "After what age would you say a man[woman] is generally too old to still be living with her or his parents". This question refers to a cultural age deadline in the spirit of Settersten and Hagestad (1996). One problem with this variable is that the interviewees can decide to give a specific value for the "age deadline" or, alternatively, to answer that "one is never too old to live with his parents" ("never"). Even tough, the percentage of "never" answers is quite high in 
some countries, the ranking obtained by dichotomizing the variable or ignoring the “never" answers are quite similar (see Aassve, Arpino and Billari 2013 that analysed this data). In the next section this variable will be used in a regression analysis limited on the UK sample after having pre-processed the data by matching. Before conducting this analysis, we tested for evidence of self-selection in the selected sample for those answering "one is never too old to live with his parents" by using an Heckman selection model. We did not find evidence for self-selection in the UK sample. Therefore we ignored the "never" category and considered the variable as numerical.

Table 3 shows a considerable variation across countries in the average values of what is considered the age deadline to still leave with parents. Moreover, in some countries we find slightly different values for the male and female target, which is an evidence of (moderate) double standards. In other countries, it seems that there is no evidence of the existence of double standards.

Matching pre-processing to study double standards: an application related to leaving home age deadlines

In this section we apply the matching pre-processing approach discussed above to the age deadline question related to leaving home. For illustrative purpose, as already said, the analysis will be limited on the UK sample. From table 3 we can see that United Kingdom is one of those countries for which we find a statistically insignificant difference in the average values of the perceived age deadlines between the samples of those answering for the male and the female target. However, the fact that overall there is no evidence of double standard does not imply that nobody in the 
UK population holds a double standard. The result might simply indicate that the prevalence of this sub-population is low or double standards of the opposite sign might compensate each other. In order to investigate on the possible heterogeneity characterizing double standards we contrast two approaches. The first one consists in implementing directly on the split-ballot data a regression analysis (we label this approach as one-step approach). Our alternative proposal consists in first preprocessing the data by matching and then applying a regression model on them (twostep approach).

We start by showing results from the second approach. We first adopted a CEM procedure to find strata of individuals with similar characteristics using the $\mathrm{R}$ software cem by Iacus, King and Porro (2009). The covariates we considered were: respondent's gender $(1=$ female; $0=$ male); age (numerical); education level achieved $(1=$ primary or less; $2=$ secondary; $3=$ post-secondary); religiosity (numerical: $0=$ not at all religious to $10=$ very religious). The numerical covariates age and religiosity were coarsened into 4 equal frequencies intervals. Then all units were assigned to one of the strata formed by combining the values of the considered variables. Finally, the algorithm, pruned from the data set the units in any stratum that did not include at least one individual assigned to the male version of the questionnaire and one assigned to the other version. Given that the gender of the target was randomly assigned, we only had few unmatched units ( 5 with $\mathrm{T}=1$ and 14 with $T=0$ ). Unmatched units were in majority females in the oldest age group. Again, given randomization of $T$, we do not expect strong unbalance in the covariates distribution between the two groups. In fact, the $L 1$ index, that is a measure of imbalance, is smaller than 0.05 for all the covariates. However, the multivariate $L 1$ 
calculated for some combination of covariates (e.g., female and education) showed higher values (0.21). After matching also interactions among all covariates were balanced. The estimated difference between the average age deadline for the two targets was 0.30 with a $95 \%$ confidence interval equal to $(-0.41 ; 1.01)$, so confirming that overall there is no statistically significant evidence of a double standard in UK. At this point it is interesting to implement a finer analysis to see if sub-groups of the population hold a double standard.

Figure 1 shows strata-level double standard estimates sorted in numerical order and colored in ranges: negative (in blue), not significantly different from zero (black), or positive (red). Negative estimates indicate that the average declared age deadline for women is higher than for man; vice versa for positive estimates. The number of non-empty strata was 62 and strata size ranged from 5 to 69 units. So, it is clear that some strata specific estimates are quite unreliable. However, the approach is useful to explore the heterogeneity existing in the data. From Figure 1 we can see that there is evidence of considerable heterogeneity: there are several strata that show positive and significant estimates, while on the other hand there are strata with negative and significant estimates. The fact that overall we do not find a significant difference between the two target is due to compensation effects between these two groups to which belong, about $30 \%$ and $24 \%$ of the matched units, respectively. The remaining $46 \%$ belongs to the "black" group, indicating that a great part of the UK population do not hold particular double standards with respect to age deadlines related to leaving home.

After having an indication of heterogeneity in the population, it is of interest to characterize the different groups. Table 4 shows some descriptive statistics by the 
three groups previously identified. Among those that tend to accept men staying at home longer, we can notice a prevalence of young females with low education. On the contrary, among those who are more "tolerant" with women we notice higher age and education. Religiosity seems not to differ much across groups. Without the matching pre-processing step this analysis would not have been possible.

To assess the statistical significance of these heterogeneities of double standards we implement a regression analysis where the outcome is the estimated individual double standard from the matching procedure described above. Table 5 shows results of this regression analysis. Model 1 only introduces baseline covariates, while model 2 also includes some interaction between the respondent gender and age and education. All the covariates, but religiosity, are significantly associated with double standards. The results of model 1 and 2 basically confirm what it was already noticed commenting on the groups covariates profiling.

An alternative approach is to implement the one-step method, i.e., a regression analysis on the observed attitude answers, including a dummy variable for gender of target $T$ among the covariates. Moreover, to have a model equivalent to Model 1, i.e., accounting for heterogeneity in double standards, a full set of interactions between $T$ and the other covariates has to be included. Results from such regression model are reported in Table 6 (Model 3). First of all, we can notice that standard errors are now much higher than in Model 1 of Table 5 and we only find significant differences by gender of the respondent. Moreover, the interpretation of results is more involved. Finally, we can notice that in order to test for interactions effects on the double standards (for example, by gender and education) as done in Model 2 of Table 5, we should have included 3-way interactions. 
Summarizing, we can notice that introducing a matching data pre-processing step simplifies the analysis of the effects of covariates on double standards and offers some additional opportunity for research on double standards.

\section{Conclusions}

In this paper we discussed the estimation and analysis of double standards using splitballot quantitative survey data. The key problem of this design is that individual double standards cannot be identified. We proposed a two-step method that simplifies the analysis of split-ballot data and offers new opportunities for research on double standards. The approach consists of a first step in which units assigned to one target group are matched with units assigned to the other target group to estimate individual double standards. Once this matching pre-processing of the data is completed, any statistical technique (e.g., cluster analysis, regression model) can be applied on the new data. We illustrated the method using data on attitudes toward age at leaving home from the third round of the European Social Survey.

We showed that the proposed method simplifies the analysis of the effect of covariates on double standards. In fact, in a regression approach typically used for this goal, full interactions between the indicator for the target and covariates are not necessary. Having estimated individual double standards, these can be directly modeled using only the main effects of covariates. If interaction effects has to be tested, 3-way interactions of the traditional approach can be substituted with 2-way interactions.

The proposed matching pre-processing approach also offers the possibility to implement analyses that otherwise could not be realized with split-ballot data. For 
example, having obtained estimates of individual double standards one can calculate the proportion of individuals that hold (different types of) double standards. As another example, in case of analyzing different dimensions, a cluster or factor analysis could be implemented on the estimated double standards for the different items.

One limitation of the approach is that in the second step one should take into account that individual double standards are estimated. The application of bootstrap methods for this scope could be explored in future research.

\section{References}

Aassve, A., Arpino, B., and Billari, F. C. (2013). Age norms on leaving home: Multilevel evidence from the European Social Survey. Environment and Planning A, 45(2), 383-401. 
Arpino, B., and Aassve, A. (2013). Estimating the causal effect of fertility on economic wellbeing: data requirements, identifying assumptions and estimation methods. Empirical Economics, 44(1), 355-385.

Crawford, M., and Popp, D. (2003). Sexual double standards: a review and methodological critique of two decades of research. Journal of Sex Research, $40,13-26$

Deutsch, F.M., and Saxon, S. E. (1998). The double standard of praise and criticism for mothers and fathers. Psychology of Women Quarterly, 22, 665-683.

Foschi, M. (1996). Double standards in the evaluation of men and women. Social Psychology Quarterly, 237-254.

Iacus, S. M., King, G., and Porro, G. (2009) CEM: Software for Coarsened Exact Matching, Journal of Statistical Software, 30.

Iacus, S. M., King, G., and Porro, G. (2011). Multivariate matching methods that are monotonic imbalance bounding. Journal of the American Statistical Association, 106(493), 345-361.

Jasso, G., and Webster, Jr. M. (1997). Double standards in just earnings for male and female workers. Social Psychology Quarterly, 66-78.

Kreager, D. A., and Staff, J. (2009). The sexual double standard and adolescent peer acceptance. Social psychology quarterly, 72(2), 143-164.

Liefbroer, A. C., and Billari, F. C. (2010). Bringing norms back in: A theoretical and empirical discussion of their importance for understanding demographic behaviour. Population, Space and Place, 16(4), 287-305. 
Loxley, W. (1996). 'Sluts' or 'Sleazy Little Animals'?: Young People's Difficulties with Carrying and Using Condoms. Journal of community \& applied social psychology, 6(4), 293-298.

Marks, M. J., and Fraley, C. R. (2006) Confirmation Bias and the Sexual Double Standard. Sex Roles, 54. 19-26.

Reid, J. A., Elliott, S., and Webber, G. R. (2011). Casual Hookups to Formal Dates Refining the Boundaries of the Sexual Double Standard. Gender \& Society, 25(5), $545-568$.

Reiss, I. L. (1964). The scaling of premarital sexual permissiveness. Journal of Marriage and the Family, 188-198.

Rijken, A. J., and Merz, E. M. (2014). Double Standards: Differences in Norms on Voluntary Childlessness for Men and Women. European sociological review, 30, 470-482.

Rubin, D. B. (1974) Estimating causal effects of treatments in randomized and nonrandomized studies, Journal of Educational Psychology, 66,688-701.

Settersten, R. A. Jr., and Hagestad, G. O. (1996) What's the latest? Cultural age deadlines for family transitions, Gerontologist, 36(2), 178-188.

Sniderman, P. M., and Grob, D. B. (1996). Innovations in experimental design in attitude surveys. Annual review of Sociology, 377-399.

Table 1. Sample sizes for all countries included in the third round of the European Social Survey by split-ballot assignment.

\begin{tabular}{lrrrrr}
\hline Country & Label & $\begin{array}{c}\mathrm{T}=0 \\
(\text { Woman })\end{array}$ & $\begin{array}{c}\mathrm{T}=1 \\
(\mathrm{Man})\end{array}$ & \multicolumn{1}{c}{$\mathrm{N}$} & \multicolumn{1}{c}{$\%$} \\
\hline Austria & AT & 1280 & 1125 & 2405 & 53.22
\end{tabular}




\begin{tabular}{|c|c|c|c|c|c|}
\hline Belgium & $\mathrm{BE}$ & 863 & 935 & 1798 & 48.00 \\
\hline Bulgaria & BG & 678 & 722 & 1400 & 48.43 \\
\hline Switzerland & $\mathrm{CH}$ & 943 & 860 & 1803 & 52.30 \\
\hline Cyprus & $\mathrm{CY}$ & 507 & 488 & 995 & 50.95 \\
\hline Germany & $\mathrm{DE}$ & 1469 & 1447 & 2916 & 50.38 \\
\hline Denmark & DK & 734 & 771 & 1505 & 48.77 \\
\hline Estonia & $\mathrm{EE}$ & 789 & 728 & 1517 & 52.01 \\
\hline Spain & ES & 959 & 917 & 1876 & 51.12 \\
\hline Finland & FI & 975 & 921 & 1896 & 51.42 \\
\hline France & FR & 1001 & 985 & 1986 & 50.40 \\
\hline United Kingdom & GB & 1213 & 1181 & 2394 & 50.67 \\
\hline Hungary & $\mathrm{HU}$ & 748 & 770 & 1518 & 49.28 \\
\hline Ireland & $\mathrm{IE}$ & 881 & 919 & 1800 & 48.94 \\
\hline Latvia & LV & 978 & 979 & 1957 & 49.97 \\
\hline Netherlands & NL & 928 & 961 & 1889 & 49.13 \\
\hline Norway & $\mathrm{NO}$ & 874 & 876 & 1750 & 49.94 \\
\hline Poland & PL & 863 & 858 & 1721 & 50.15 \\
\hline Portugal & PT & 1144 & 1078 & 2222 & 51.49 \\
\hline Romania & RO & 1074 & 1065 & 2139 & 50.21 \\
\hline Russian Federation & RU & 1218 & 1219 & 2437 & 49.98 \\
\hline Sweden & $\mathrm{SE}$ & 947 & 980 & 1927 & 49.14 \\
\hline Slovenia & SI & 715 & 761 & 1476 & 48.44 \\
\hline Slovakia & SK & 867 & 899 & 1766 & 49.09 \\
\hline Ukraine & UA & 1089 & 913 & 2002 & 54.40 \\
\hline Total & & 23737 & 23358 & 47095 & 50.40 \\
\hline
\end{tabular}

Note: $\mathrm{T}$ stands for gender of target, $\mathrm{N}$ is the total country sample size and $\%$ is the percentage of people assigned to the woman target questionnaire. 
Table 2. Mean values of importance of different events to be considered an adult, by country and gender of target.

\begin{tabular}{|c|c|c|c|c|c|c|c|c|c|c|c|c|c|c|c|c|}
\hline \multirow{2}{*}{ Country } & \multicolumn{4}{|c|}{ Partner } & \multicolumn{4}{|c|}{ Parent } & \multicolumn{4}{|c|}{ Leaving Home } & \multicolumn{4}{|c|}{ Job } \\
\hline & Man & Woman & Diff. & Sign. & Man & Woman & Diff. & Sign. & Man & Woman & Diff. & Sign. & Man & Woman & Diff. & Sign. \\
\hline $\mathrm{AT}$ & 2.79 & 2.45 & 0.35 & $* * *$ & 2.54 & 2.41 & 0.13 & $* *$ & 3.44 & 3.01 & 0.43 & $* * *$ & 3.88 & 3.00 & 0.88 & $* * *$ \\
\hline $\mathrm{BE}$ & 2.52 & 2.31 & 0.21 & $* * *$ & 2.63 & 2.51 & 0.13 & $* *$ & 2.74 & 2.48 & 0.26 & $* * *$ & 3.56 & 2.83 & 0.72 & $* * *$ \\
\hline BG & 3.55 & 3.44 & 0.11 & $*$ & 3.78 & 3.85 & -0.06 & & 2.72 & 2.74 & -0.02 & & 3.93 & 3.63 & 0.29 & $* * *$ \\
\hline $\mathrm{CH}$ & 2.57 & 2.29 & 0.29 & $* * *$ & 2.80 & 2.54 & 0.26 & $* * *$ & 3.08 & 2.77 & 0.31 & $* * *$ & 3.14 & 2.65 & 0.50 & $* * *$ \\
\hline $\mathrm{CY}$ & 2.94 & 2.79 & 0.15 & $* *$ & 3.07 & 3.10 & -0.03 & & 2.70 & 2.66 & 0.04 & & 3.54 & 3.14 & 0.40 & $* * *$ \\
\hline $\mathrm{DE}$ & 2.67 & 2.53 & 0.14 & $* * *$ & 2.82 & 2.82 & 0.00 & & 2.83 & 2.68 & 0.15 & $* * *$ & 3.05 & 2.73 & 0.32 & $* * *$ \\
\hline DK & 2.66 & 2.39 & 0.27 & $* * *$ & 3.10 & 2.97 & 0.13 & $*$ & 3.67 & 3.30 & 0.38 & $* * *$ & 3.16 & 2.76 & 0.40 & $* * *$ \\
\hline $\mathrm{EE}$ & 2.91 & 2.66 & 0.25 & $* * *$ & 2.98 & 2.83 & 0.15 & $* *$ & 3.13 & 2.80 & 0.33 & $* * *$ & 3.74 & 2.99 & 0.75 & $* * *$ \\
\hline ES & 2.22 & 2.08 & 0.14 & $* *$ & 2.38 & 2.27 & 0.11 & $*$ & 2.37 & 2.31 & 0.06 & & 2.76 & 2.40 & 0.36 & $* * *$ \\
\hline FI & 2.62 & 2.23 & 0.38 & $* * *$ & 2.31 & 2.05 & 0.25 & $* * *$ & 3.43 & 2.92 & 0.51 & $* * *$ & 3.36 & 2.81 & 0.55 & $* * *$ \\
\hline FR & 2.74 & 2.57 & 0.16 & $* * *$ & 3.11 & 2.94 & 0.17 & $* * *$ & 3.16 & 2.85 & 0.31 & $* * *$ & 3.88 & 3.32 & 0.56 & $* * *$ \\
\hline GB & 2.41 & 2.17 & 0.24 & $* * *$ & 2.44 & 2.24 & 0.20 & $* * *$ & 2.91 & 2.52 & 0.39 & $* * *$ & 3.57 & 2.72 & 0.85 & $* * *$ \\
\hline $\mathrm{HU}$ & 2.16 & 2.06 & 0.10 & & 2.05 & 2.11 & -0.06 & & 2.28 & 1.98 & 0.30 & $* * *$ & 3.05 & 2.45 & 0.61 & $* * *$ \\
\hline IE & 2.42 & 2.06 & 0.36 & $* * *$ & 2.41 & 2.15 & 0.26 & $* * *$ & 2.86 & 2.39 & 0.47 & $* * *$ & 3.61 & 2.76 & 0.85 & $* * *$ \\
\hline LV & 2.91 & 2.90 & 0.00 & & 3.02 & 3.11 & -0.09 & & 2.80 & 2.69 & 0.12 & $* *$ & 3.23 & 2.86 & 0.37 & $* * *$ \\
\hline NL & 2.33 & 2.17 & 0.15 & $* * *$ & 2.36 & 2.21 & 0.15 & $* * *$ & 2.80 & 2.49 & 0.31 & $* * *$ & 2.83 & 2.42 & 0.41 & $* * *$ \\
\hline NO & 2.25 & 1.91 & 0.34 & $* * *$ & 2.25 & 1.98 & 0.27 & $* * *$ & 3.31 & 2.91 & 0.40 & $* * *$ & 3.09 & 2.47 & 0.62 & $* * *$ \\
\hline PL & 3.08 & 2.89 & 0.19 & $* * *$ & 3.17 & 3.16 & 0.02 & & 2.71 & 2.53 & 0.18 & $* * *$ & 3.43 & 2.94 & 0.49 & $* * *$ \\
\hline PT & 3.37 & 3.39 & -0.02 & & 3.58 & 3.64 & -0.06 & & 3.06 & 3.08 & -0.02 & & 3.47 & 3.39 & 0.08 & $*$ \\
\hline RO & 3.21 & 3.21 & 0.01 & & 3.36 & 3.36 & -0.01 & & 2.84 & 2.74 & 0.10 & $* *$ & 3.61 & 3.34 & 0.28 & $* * *$ \\
\hline RU & 3.36 & 3.29 & 0.06 & & 3.58 & 3.58 & 0.00 & & 3.27 & 2.99 & 0.27 & $* * *$ & 3.38 & 3.14 & 0.25 & $* * *$ \\
\hline SE & 2.07 & 1.74 & 0.33 & $* * *$ & 2.05 & 1.76 & 0.28 & $* * *$ & 3.37 & 2.69 & 0.68 & $* * *$ & 2.78 & 2.19 & 0.59 & $* * *$ \\
\hline SI & 2.73 & 2.40 & 0.33 & $* * *$ & 2.71 & 2.58 & 0.13 & $* *$ & 2.88 & 2.50 & 0.38 & $* * *$ & 3.40 & 2.89 & 0.51 & $* * *$ \\
\hline SK & 2.58 & 2.31 & 0.26 & $* * *$ & 2.52 & 2.48 & 0.04 & & 2.51 & 2.23 & 0.28 & $* * *$ & 3.51 & 2.92 & 0.59 & $* * *$ \\
\hline UA & 3.40 & 3.28 & 0.12 & $* *$ & 3.70 & 3.59 & 0.11 & $* *$ & 3.21 & 3.00 & 0.21 & $* * *$ & 3.52 & 3.23 & 0.30 & $* * *$ \\
\hline Total & 2.74 & 2.55 & 0.18 & $* * *$ & 2.82 & 2.73 & 0.09 & $* * *$ & 2.97 & 2.71 & 0.27 & $* * *$ & 3.37 & 2.88 & 0.49 & $* * *$ \\
\hline
\end{tabular}

Note: The questions read as "To be considered an adult how important is it for a [man/woman] to [have lived with a spouse or partner/ become a [father/mother]/ have left the parental home/ have a full-time job/]. Answers can be given on a 5-point scale ranging from $1=$ "Not at all important" to $5=$ "Very important". 
Table 3. Mean age too old to still be leaving with parents, by gender of target.

\begin{tabular}{lccclr}
\hline Country & T=Man & T=Woman & Diff. & Sign. & \% Diff. \\
\hline Austria & 29.06 & 28.05 & 1.00 & $* * *$ & 3.45 \\
Belgium & 29.54 & 28.81 & 0.74 & $* * *$ & 2.49 \\
Bulgaria & 28.28 & 28.08 & 0.20 & & 0.69 \\
Switzerland & 27.58 & 26.78 & 0.80 & $* * *$ & 2.90 \\
Cyprus & 32.79 & 31.71 & 1.07 & $* * *$ & 3.27 \\
Germany & 27.76 & 27.08 & 0.68 & $* * *$ & 2.45 \\
Denmark & 24.47 & 23.98 & 0.49 & $* *$ & 2.00 \\
Estonia & 27.38 & 26.61 & 0.77 & $* *$ & 2.83 \\
Spain & 30.77 & 30.15 & 0.62 & $* *$ & 2.02 \\
Finland & 25.88 & 25.49 & 0.39 & & 1.50 \\
France & 27.91 & 27.61 & 0.30 & & 1.08 \\
United Kingdom & 28.52 & 28.17 & 0.35 & & 1.22 \\
Hungary & 30.48 & 29.74 & 0.74 & $*$ & 2.42 \\
Ireland & 28.32 & 28.34 & -0.02 & $* * *$ & -0.08 \\
Latvia & 28.56 & 28.61 & -0.05 & & -0.17 \\
Netherlands & 28.29 & 27.71 & 0.58 & $* *$ & 2.05 \\
Norway & 26.23 & 25.95 & 0.28 & & 1.06 \\
Poland & 28.49 & 27.63 & 0.86 & $* * *$ & 3.00 \\
Portugal & 31.18 & 31.31 & -0.13 & & -0.41 \\
Romania & 30.03 & 29.41 & 0.62 & $*$ & 2.05 \\
Russian Federation & 23.94 & 23.66 & 0.28 & & 1.17 \\
Sweden & 26.16 & 25.95 & 0.22 & & 0.84 \\
Slovenia & 23.74 & 29.18 & 0.56 & $*$ & 1.88 \\
Slovakia & 29.71 & 0.47 & & 1.55 \\
Ukraine & 27.44 & 0.52 & $* * *$ & 1.86 \\
\hline Total & 28.74 & $* * *$ & 3.13 \\
\hline & 28.01 & & & \\
\hline
\end{tabular}


Table 4. Covariates profiling of three groups with different double standards towards age at leaving home.

\begin{tabular}{lrrrr}
\hline & \multicolumn{3}{c}{ Group double standards } & \\
\cline { 2 - 4 } Covariate & Women & No double & Men can & Total \\
& can stay & stay & \\
& longer & standards & longer & \\
\hline Age & 50.79 & 49.00 & 40.93 & 47.03 \\
Age_category_1 & 0.11 & 0.23 & 0.40 & 0.25 \\
Age_category_2 & 0.33 & 0.23 & 0.23 & 0.25 \\
Age_category_3 & 0.32 & 0.26 & 0.17 & 0.25 \\
Age_category_4 & 0.25 & 0.28 & 0.20 & 0.25 \\
Female & 0.26 & 0.61 & 0.70 & 0.55 \\
Edu_category_1 & 0.24 & 0.59 & 0.46 & 0.47 \\
Edu_category_2 & 0.26 & 0.17 & 0.27 & 0.22 \\
Edu_category_3 & 0.50 & 0.25 & 0.27 & 0.32 \\
Religiosity & 3.47 & 4.54 & 3.51 & 3.98 \\
Religiosity_category_1 & 0.34 & 0.12 & 0.14 & 0.18 \\
Religiosity_category_2 & 0.14 & 0.28 & 0.37 & 0.28 \\
Religiosity_category_3 & 0.33 & 0.28 & 0.37 & 0.32 \\
Religiosity_category_4 & 0.19 & 0.31 & 0.12 & 0.23 \\
\hline Sample size & 379 & 723 & 467 & 1569 \\
\% & 24.16 & 46.08 & 29.76 & 100.00 \\
\hline
\end{tabular}

Note: age and religiosity categories are binary variables roughly corresponding to inter-quartiles ranges; education categories correspond to Primary or less, Secondary or Post-secondary education levels. 
Table 5. Double standards towards age at leaving home: regression results after matching pre-processing.

\begin{tabular}{|c|c|c|c|c|c|c|}
\hline \multirow{2}{*}{ Covariates } & \multicolumn{3}{|c|}{ Model 1} & \multicolumn{3}{|c|}{ Model 2} \\
\hline & Coef. & S.E. & Sign. & Coef. & S. E. & Sign. \\
\hline Female & 1.29 & 0.42 & $* * *$ & 2.64 & 0.93 & $* * *$ \\
\hline Age & -0.03 & 0.01 & $* *$ & -0.01 & 0.00 & $* * *$ \\
\hline Edu_category_1 & 0.95 & 0.38 & $* *$ & 1.48 & 0.50 & $* * *$ \\
\hline Edu_category_2 & 0.46 & 0.23 & $* *$ & 0.46 & 0.20 & $* *$ \\
\hline Religiosity_category_1 & -0.31 & 0.58 & & -0.30 & 0.58 & \\
\hline Religiosity_category_2 & 0.77 & 0.47 & & 0.79 & 0.46 & $*$ \\
\hline Religiosity_category_3 & 0.47 & 0.56 & & 0.47 & 0.53 & \\
\hline Female*Age & & & & -0.02 & 0.01 & $* *$ \\
\hline Female*Edu_category_1 & & & & -0.94 & 0.46 & $* *$ \\
\hline Female*Edu_category_2 & & & & -0.02 & 0.43 & \\
\hline Constant & -0.03 & 0.77 & & -0.80 & 0.83 & \\
\hline
\end{tabular}

Note: standard errors are clustered at the CEM strata level. 
Table 6. Double standards towards age at leaving home: regression results without matching pre-processing.

\begin{tabular}{|c|c|c|}
\hline \multirow{2}{*}{ Covariates } & \multicolumn{2}{|c|}{ Model 3} \\
\hline & Coef. & S. E. Sign. \\
\hline Female & 0.63 & 0.41 \\
\hline Age & -0.01 & 0.01 \\
\hline Edu_category_1 & 0.36 & 0.48 \\
\hline Edu_category_2 & 0.53 & 0.56 \\
\hline Religiosity_category_1 & -0.48 & 0.66 \\
\hline Religiosity_category_2 & 0.13 & 0.59 \\
\hline Religiosity_category_3 & 1.14 & 0.57 \\
\hline Target & 0.04 & 1.09 \\
\hline Target*Female & 1.01 & $0.56 *$ \\
\hline Target*Age & -0.01 & 0.02 \\
\hline Target*Edu_category_1 & 0.60 & 0.65 \\
\hline Target*Edu_category_2 & -0.02 & 0.77 \\
\hline Target* Religiosity_category_1 & -0.12 & 0.89 \\
\hline Target* Religiosity_category_2 & 0.60 & 0.80 \\
\hline Target* Religiosity_category_3 & -0.42 & 0.76 \\
\hline Constant & 27.54 & $0.80 * * *$ \\
\hline
\end{tabular}


Figure 1. Strata-level estimates of double standards towards age at leaving home ordered by magnitude and colored by sign and statistical significance.

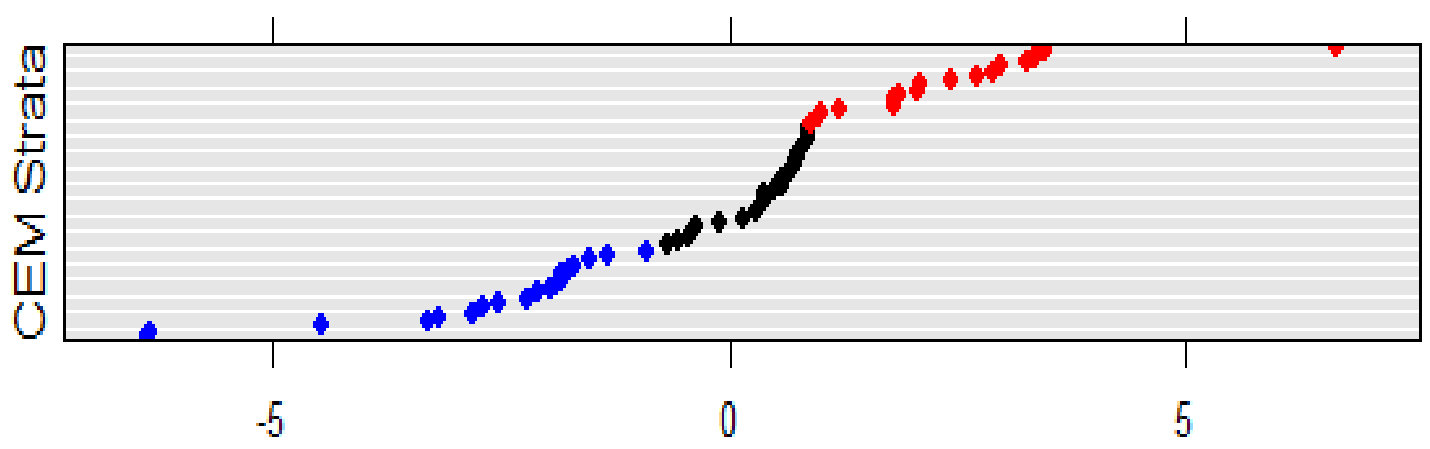

Note: blue $=$ negative (women can stay longer) and statistically significant estimates; black $=$ not statistically different from zero; red $=$ positive (men can stay longer) and statistically significant. Strata sample sizes range from 5 to 69 . Overall sizes of blue, black and red groups are respectively 379, 723 and 467. 